\title{
BLOOD LOSS AND TRANSCAPILLARY REFILL IN UNCONTROLLED TREATED HEMORRHAGE IN DOGS
}

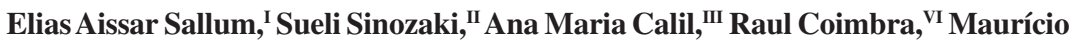 \\ Rocha E Silva, ${ }^{\text {II }}$ Luis Francisco Poli de Figueiredo, ${ }^{V}$ Dario Birolini ${ }^{\mathrm{I}}$
}

doi: $10.1590 / \mathrm{S} 1807-59322010000100011$

Sallum EA, S Sinozaki, Calil AM, Coimbra R, Rocha E Silva M, Poli de Figueiredo LF, Birolini D. Blood loss and transcapillary refill in uncontrolled treated hemorrhage in dogs. Clinics. 2010;65(1):67-78.

OBJETIVE: This study evaluated retroperitoneal hematomas produced by bilateral injury of iliac arteries (uncontrolled hemorrhage), blood volume loss, transcapillary refill, the effects of volume replacement on retroperitoneal bleeding and the hemodynamic changes with and without treatment.

METHODS: Initial blood volume was determined with $\mathrm{Tc}^{99 \mathrm{~m}}$-labelled red cells, and bleeding was evaluated by means of a portable scintillation camera positioned over the abdomen. Previously splenectomized mongrel dogs $(16.8 \pm 2.2 \mathrm{~kg})$ were submitted to hemorrhage for 30 minutes and randomized into three groups: I - no treatment ( $\mathrm{n}=7$ ); II - treatment with $32 \mathrm{~mL} / \mathrm{kg}$ of Lactated Ringer's for three to five minutes (n=7); and III - treatment with $4 \mathrm{~mL} / \mathrm{kg}$ of $7.5 \% \mathrm{NaCl}$ plus $6.0 \%$ dextran 70 for three to five minutes $(n=7)$. They were studied for an additional 45 minutes.

RESULTS: Volume replacement produced transitory recovery in hemodynamic variables, including mean pulmonary artery pressure, pulmonary capillary wedge pressure and cardiac index, with significant increase in dogs treated with $32 \mathrm{~mL} / \mathrm{kg}$ of Lactated Ringer's and $7.5 \% \mathrm{NaCl}$ plus $6.0 \%$ dextran 70 ( $\mathrm{p}<0.001$, against no treatment), along with a decrease $(\mathrm{p}<0.001)$ in the systemic vascular resistance index. Groups II and III had significant initial decreases in hematocrit and hemoglobin. The treated dogs (groups II and III) presented rebleeding, which was greater during treatment with $32 \mathrm{~mL} / \mathrm{kg}$ of Lactated Ringer's (group II).

CONCLUSIONS: Despite the rebleeding observed in treated groups, the utilization of hypertonic saline solution with dextran proved to be effective in the initial reanimation, producing evident transcapillary refill, while the Lactated Ringer's solution produced capillary extravasation and was ineffective in the initial volume replacement in this model of uncontrolled hemorrhage.

KEYWORDS: Retroperitoneal hematoma; Uncontrolled hemorrhage; Shock; Hypertonic saline solution; Small volume resuscitation.

\section{INTRODUCTION}

Volume resuscitation has been the mainstay of treatment

\footnotetext{
${ }^{\text {I }}$ Departamento de Cirurgia, Divisão de Cirurgia Geral do Hospital das Clínicas da Faculdade de Medicina da Universidade de São Paulo - São Paulo/SP, Brazil.

II Departamento de Cirurgia, Divisão de Cirurgia Experimental do Instituto do Coração (INCOR) - São Paulo/SP, Brazil.

IIIEscola de Enfermagem da Universidade de São Paulo - São Paulo/SP, Brazil.

Iv Departamento de Cirurgia, Divisão de Trauma da Universidade de San

Diego Califórnia/USA.

v Departamento de Cirurgia, Divisão de Técnica Cirúrgica do Hospital das Clínicas da Faculdade de Medicina da Universidade de São Paulo - São Paulo/SP, Brasil.

Email: easallum.fnr@terra.com.br

Tel: 55113289.3343

Received for publication on September 13, 2009

Accepted for publication on October 20, 2009
}

for hypotensive trauma victims. ${ }^{1}$ However, controversy remains because there are concerns that this approach, before the control of bleeding, may result in increased blood loss due to increased blood pressure, which would dislodge blood clots, and the dilution of clotting factors. ${ }^{2-5}$

Hypotensive resuscitation and no fluid regimens are some strategies for avoidance of the potential side effects of volume infusion in uncontrolled hemorrhage..$^{2,3,5,6}$ On the other hand, studies using small volumes of hypertonic saline or hypertonic saline plus dextran (HSD) have shown hemodynamic benefits and no significant increase in blood loss in several models of uncontrolled hemorrhage..$^{7-15}$ None of the clinical studies evaluating hypertonic saline or hypertonic saline plus dextran (HSD) as the first fluid volumes infused into hypotensive 
patients suggested increased bleeding. On the contrary, these studies systematically suggest that hemodynamic benefits are achieved with less fluid and blood products in comparison to what is required for standard isotonic resuscitation. ${ }^{15-24}$

In the present study, we promoted a retroperitoneal hemorrhage with class III shock by ATLS with a simulation of blunt abdominal injury ${ }^{1,25-27}$ by bilateral posterior iliac artery puncture to evaluate fluid shifts and blood loss after HSD or isotonic saline infusion, in comparison to no fluid replacement. Our hypothesis is that small volumes of HSD promote volume expansion and hemodynamic benefits, in spite of modest increases in blood loss.

\section{MATERIALS AND METHODS}

This project was previously approved by the Ethics Committee of the Heart Institute and conforms to National Institutes of Health guidelines for the use of experimental animals.

\section{Surgical preparation}

Experiments were performed on 21 male mongrel dogs weighing $16.8 \pm 2.2 \mathrm{~kg}$ (STD DEV) that had been splenectomized under sterile conditions three days before the experiment, under $2 \%$ halothane anesthesia to avoid the effect of splenic contraction and release of red cells to the circulation during shock.

Dogs were fed standard dog chow and water ad libitum in the divisional kennel. Food was removed $12 \mathrm{~h}$ prior to the experiment, and water was discontinued $1 \mathrm{~h}$ before intravenous anesthesia with $1.5 \mathrm{mg} / \mathrm{kg}$ of morphine and 25 $\mathrm{mg} / \mathrm{kg}$ of pentobarbital sodium. Animals were endotracheally intubated and mechanically ventilated $\left(\mathrm{FiO}_{2}=50 \%, \mathrm{TV}=10\right.$ $\mathrm{cc} / \mathrm{kg}$, respiratory rate $=12 \mathrm{rpm}$ ) during the whole experiment. An arterial blood sample was drawn before the experiments and used to adjust the ventilator settings.

The following interventions were performed through cutdown incisions: 1) bilateral femoral artery dissection for the introduction of Veress needles positioned under radioscopy with their tips at the level of the $6^{\text {th }}-7^{\text {th }}$ vertebral body to create a retroperitoneal hematoma (see description of the experimental model below); 2) A 5F triple lumen Swan-Ganz catheter (Baxter Health Care Corporation) was introduced through the right internal jugular. The tip of the catheter was positioned into the pulmonary artery under fluoroscopic guidance and pressure wave analysis. The catheter was connected to a pressure monitor (MP 100 WSW, Biopac System, USA), and all pressure measurements were stored in a computer system
(Acknowledge III) for analysis as well as for the collection of mixed venous blood; 3) Large bore (P240) polyethylene cannulae were inserted into the right common carotid artery and connected to a strain gauge transducer coupled to a model 1290-CP recorder to control mean arterial pressure; 4) A short catheter number 14 was inserted into the left external jugular vein for $\mathrm{Tc}^{99 \mathrm{~m}}$ infusion and volume replacement; 5) A 4F Foley catheter was used for urinary output monitoring.

\section{Hemorrhage Model}

The hemorrhage model of a retroperitoneal hematoma utilized in the present study was initially described by Cruz $\mathrm{Jr}^{28}$ Briefly, after dissection of both femoral arteries in the groin, a Veress needle was introduced into each artery, advanced towards the common iliac artery under fluoroscopic visualization and pushed against the posteriorlateral wall of the vessel to create an injury.

At the end of the experiment, animals were sacrificed by an intravenous injection of pentobarbital $(50 \mathrm{mg} / \mathrm{kg})$, followed by $20 \mathrm{ml}$ of $19.1 \% \mathrm{KCl}$. An autopsy was performed to document the severity and extent of the retroperitoneal hematoma and the size and location of the iliac artery injury. The iliac arteries were dissected free, and each perforation created by the Veress needle was measured.

Exclusion criteria included: a) animals with initial hemoglobin levels $<10 \mathrm{~g} / \mathrm{dL}, \mathrm{b}$ ) arterial injuries $\leq 5 \mathrm{~mm}, \mathrm{c}$ ) extension of the hematoma greater than the area of image acquisition of the gamma camera, d) peritoneal perforation with subsequent bleeding into the peritoneal cavity, and e) mean arterial pressure (MAP) 50\% higher than initial MAP five minutes after arterial injury.

The study was divided into two phases.

\section{Phase I: Development of a method for the quantifica- tion of blood loss.}

\section{Experiment A - Physical Simulation}

Physical simulation was performed to verify the reliability of quantifying a known, pre-determined volume of fluid using sequential gamma camera image acquisitions. Initially, a plastic syringe filled with $10 \mathrm{~mL}$ of water, containing ${ }^{99 \mathrm{~m}}$ Technetium ${ }^{99 \mathrm{~m}} \mathrm{Tc}$, Instituto de Pesquisas Energéticas e Nucleares/CNEN, Universidade de São Paulo, Brazil) with a known amount of radioactivity $(2 \mathrm{mCi})$ was placed under the gamma camera and radioactivity was measured. A plastic bag was then filled with successive $50 \mathrm{~mL}$ aliquots of water containing ${ }^{99 \mathrm{~m}} \mathrm{Tc}(2 \mathrm{mCi})$ up to a total volume of $1300 \mathrm{~mL}$. Radioactivity in the 
syringe was compared with that in the plastic bag to establish a correction factor accounting for the geometry of the bag containing larger amounts of radiolabeled fluid. Measurements were performed in triplicate.

The following equation describes the correction factor used by ROCHA (1976) ${ }^{29}$ for the measurement of radioactivity in the plastic bag containing ${ }^{99 \mathrm{~m}} \mathrm{Tc}$ dissolved in water:

$R C=M C \times e^{(0.15 \times D \times C F)}$

where RC is the radioactivity in the bag ("real" count); $\mathrm{MC}$ is the measured radioactivity; 0.15 is the attenuation factor for water; D is the thickness of the bag; and CF is the required correction factor. An operative value for $\mathrm{CF}$ was determined from averaged $\mathrm{RC}$ values within the expected range of blood loss in the retroperitoneal hematoma.

\section{Experiment B - Artificially Created Retroperitoneal Hematoma}

This set of experiments was performed to establish the correction factor due to photon attenuation caused by the presence of the abdominal wall and intra-abdominal contents in the quantification of an artificially created retroperitoneal hematoma of a known, pre-determined volume ${ }^{29}$.

Five male mongrel dogs weighing $16.8 \pm 2.6 \mathrm{~kg}$ were used. Blood $(250 \mathrm{~mL})$ was withdrawn and radiolabeled with ${ }^{99 \mathrm{~m}}$ Tc ( ${ }^{99 \mathrm{~m}}$ Tc - TCK-11, CIS Bio International, France, ${ }^{99 \mathrm{~m}} \mathrm{Tc}$ activity of $2 \mathrm{mCi}$, Instituto de Pesquisa de Energia Nuclear, Universidade de São Paulo, Brazil). A syringe containing $10 \mathrm{~mL}$ of labeled blood was kept aside, and an image was acquired at the end of each experiment for radioactivity measurements.

Following a midline laparotomy, two polyethylene catheters (PE240) were positioned in the area where a retroperitoneal hematoma secondary to bilateral iliac artery injury would be located. The abdominal wall was then closed, and the catheters were subsequently used to inject aliquots of $50 \mathrm{~mL}$ of blood mixed with ${ }^{99 \mathrm{~m}} \mathrm{Tc}$-labeled red blood cells into the retroperitoneal space.

Radioactivity measurements were performed successively, at five-minute intervals following blood injection. The volume of the retroperitoneal hematoma was calculated as described in Experiment A, accounting for the dorsoventral thickness of the abdominal wall of the animal. In this set of experiments, the injected volume was limited to a maximum of $200 \mathrm{~mL}$ because the sutures securing the catheters in place were not reliably tight for volumes greater than $200 \mathrm{~mL}$.

\section{Experiment C - In Vivo Retroperitoneal Hematoma}

This set of experiments was performed to determine the volume of blood present in a retroperitoneal hematoma (VRPH) in vivo. In one group of animals, a gamma camera and ${ }^{99 \mathrm{~m}} \mathrm{Tc}$-radiolabeled red blood cells were used to determine the blood volume present in the retroperitoneal hematoma [GC group ( $\mathrm{n}=7)$ ]. In another group, the dilution technique with ${ }^{99 \mathrm{~m}} \mathrm{Tc}$ - and Chromium $\left({ }^{51} \mathrm{Cr}\right.$, Instituto de Pesquisas Energéticas e Nucleares/CNEN, Universidade de São Paulo, Brazil, $200 \mu \mathrm{Ci}$ )-radiolabeled red blood cells was used to quantify the initial and final circulating blood volumes $(\mathrm{CBV})$, respectively [DT group $(\mathrm{n}=5)]$.

\section{Quantification of Bleeding Volume}

A portable gamma camera (Elscint, model Apex 209M, Israel) with a parallel collimator was positioned $5 \mathrm{~cm}$ above the abdomen, centered over the putative area of the retroperitoneal hematoma. Images were acquired over $5 \mathrm{~min}$ at 15-min intervals throughout the experiment. At the end of each experiment, the cumulative radioactivity for each measurement was analyzed. Because of the short half-life of ${ }^{99 \mathrm{~m}} \mathrm{Tc}$ (six hours), all counts were corrected for activity decay in the standard fashion.

\section{Measurement of initial circulating red blood cell vol- ume and total blood volume}

Initial circulating red blood cell volume (CRCV) was determined by means of isotope dilution of the radioactive tracer technetium $\left({ }^{99 \mathrm{~m}} \mathrm{Tc}\right)$, as applied by Kowalsky and Perry, 1987. ${ }^{30}$ Previously-labeled red blood cells $(3 \mathrm{~mL})$ containing a known total load of tracer (L) were injected into the systemic circulation and allowed to mix uniformly over a period of $15 \mathrm{~min}$. A syringe containing $10 \mathrm{~mL}$ of labeled blood was kept aside, and a radioactivity measurement of the sample was obtained at the end of each experiment to establish the baseline count of radioactive tracer per $\mathrm{mL}$. A separate blood sample was collected for determination of the initial hematocrit (Htc) and for determining tracer concentration (C) using a scintillation counter (Phillips Medical System Division, model XL 1100 and XL 1151, Eindhoven, Netherlands). CRCV was calculated according to the following equation:

$$
C R C V=\frac{L}{C}
$$

The circulating blood volume (CBV) was calculated as demonstrated below: 


$$
C B V=\frac{C R C V}{0.96 \times H t c}
$$

Plasma volume (PV) was determined by subtracting CRCV from CBV.

\section{Phase II. Resuscitated uncontrolled hemorrhage}

\section{Experiment D - in vivo retroperitoneal hematoma fol-} lowed by fluid resuscitation

The experiments were initiated 15 minutes after the injection of ${ }^{99 m}$ Tc-labeled red cells, when the first radioactivity measurement was obtained using the gamma camera (baseline measurement value, Figure 3). The arterial lesions were subsequently created (T0).

The experiment lasted a total of 75 minutes, during which six radioactivity measurements, 15 minutes apart, were obtained (T0, T15, T30, T45, T60, T75). Coinciding with the time of each radioactivity measurement, mean arterial pressure (MAP) and cardiac index (CI) were determined, and arterial blood samples were obtained for Htc measurements.

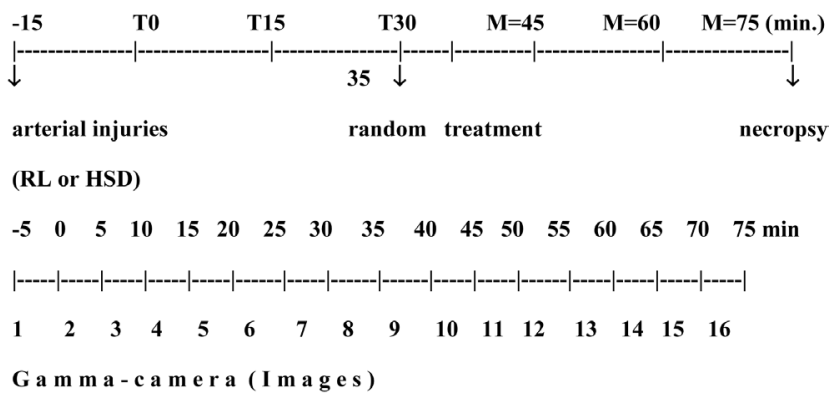

Scheme 1 - SCHEME OF EXPERIMENTAL MOMENTS

\section{Study groups}

Five minutes before T30, the animals were randomly assigned to one of three groups, according to the fluid resuscitation regimen: NT, untreated controls $(n=7)$ in which the animals underwent bilateral iliac artery injury and were observed for 75 min without any fluid resuscitation; LR $(\mathrm{n}=7)$ in which the animals received $32 \mathrm{~mL} / \mathrm{kg}$ of lactated Ringer's; or HSD ( $\mathrm{n}=7)$, in which animals received $4 \mathrm{~mL} / \mathrm{kg}$ of $7.5 \% \mathrm{NaCl}, 6 \%$ Dextran 70 in five minutes, and followed up to $75 \mathrm{~min}$.

\section{Volume of Red Cells in the Hematoma (VRCH)}

The VRCH was calculated considering the initial circulating red blood cell volume (CRCV) determined by the dilution technique and the VRPH, as described in
Experiment C. Before fluid resuscitation (T30), the VRCH was calculated as follows ${ }^{30}$ :

$\operatorname{VRCH}(T x)=\frac{\operatorname{VRPH}(T x)}{\operatorname{Htc}(T 0)}$

For all time points after fluid resuscitation, the VRCH was calculated according to the following equation ${ }^{30}$ :

$$
\operatorname{VRCH}(T x)=\operatorname{VRCH}(T 30)+\left[\frac{\operatorname{VRPH}(T x)-\operatorname{VRPH}(T 30)}{H t c(T 45)}\right]
$$

where $T x$ is the time point of the actual measurement.

\section{Volume of Retroperitoneal Hematoma (VRPH)}

Before fluid resuscitation (T30), the VRPH ( $\mathrm{mL} / \mathrm{kg}$ ) was calculated according to the following equation ${ }^{30}$ :

$$
\operatorname{VRPH}(T x)=\frac{\operatorname{VRCH}(T x)}{H t c(T 0)}
$$

After fluid resuscitation, the VRPH was calculated as follows ${ }^{30}$ :

$$
\operatorname{VRPH}(T x)=\operatorname{VRPH}(T 30)+\left[\frac{\operatorname{VRCH}(T x)-V R C H(T 30)}{H t c(T 45)}\right]
$$

\section{Circulating Red Cell Volume (CRCV)}

The CRCV $(\mathrm{mL} / \mathrm{kg}$ ) was determined by the difference between the initial circulating red cell volume (CRCV) and the VRPH.

\section{Circulating Blood Volume (CBV)}

The CBV (mL/kg) at a specific time point (Tx) was calculated by dividing the CRVC (Tx) by the Htc (Tx).

\section{Expected Circulating Blood Volume (ECBV)}

The ECBV $(\mathrm{mL} / \mathrm{kg})$ at Tx was calculated as the difference between the initial CBV and the VRPH at Tx until T30. After volume resuscitation (T45 and beyond), ECBV for the LR group was calculated as follows:

$$
E C B V(T x)=C B V(T 0)-V R P H(T x)+V I
$$

where VI is the volume of the resuscitation fluid used, i.e., $32 \mathrm{~mL} / \mathrm{kg}$ for LR- and $4 \mathrm{~mL} / \mathrm{kg}$ for HSD-resuscitated animals.

\section{Transcapillary Refill (TR)}

TR ( $\mathrm{mL} / \mathrm{kg})$ was calculated as follows:

$$
T R(T x)=C B V(T x)-E C B V(T x)
$$

Volume of Retroperitoneal Bleeding Before Fluid Resuscitation (VRB shock) 
The VRB shock (\% of CRCV) caused by the arterial injuries was calculated from T0 to T30 as follows:

$T R(T x)=C B V(T x)-E C B V(T x)$

Volume of Retroperitoneal Bleeding After Fluid Resuscitation (VRBresus)

The VRBresus occurring after fluid resuscitation (from $\mathrm{T} 30$ to T75) was calculated as follows:

$$
\operatorname{VRBresus}(\%)=\frac{[C R V C(T 30)-C R V C(T 75)] \times 100}{C R V C(T 30)}
$$

\section{Statistical analysis}

Data are presented as the mean \pm standard error of the mean. For comparisons of continuous variables, either the Student's t-test or two-way analysis of variance (ANOVA) with Turkey's B correction for multiple comparisons was used. A $p$ value $<0.05$ was considered statistically significant.

\section{RESULTS}

Phase I: Development of a method for the quantification of blood loss.

\section{Experiment A - Physical Simulation and Experiment B - Artificially-Created Retroperitoneal Hematoma}

A final CF value of 0.015 was determined after averaging $\mathrm{RC}$ values obtained from multiple measurements (see methods). A comparison between a known volume in the plastic bag and the calculated volume based on radioactivity measurements by the gamma camera (Experiment A) was made. For a volume of $50 \mathrm{~mL}$, the observed averaged error was $17 \%$, and the error was greater than $8 \%$ for volumes larger than $800 \mathrm{~mL}$. A significant correlation was observed between the expected and the measured volumes of fluid in the bag, within a range of $100-800 \mathrm{~mL}$, with a calculated error of less than $3 \%$ (Figure 1).

The range of variation for calculated values obtained from sequential radioactivity measurements in this phase was between $4 \%$ and $6 \%$ from the mean. Because results of measurements obtained during Experiment A were reliably linear within the $100 \mathrm{~mL}$ to $900 \mathrm{~mL}$ range, and because blood volumes in the retroperitoneum following induction of a hematoma ranged from $400 \mathrm{~mL}$ to $600 \mathrm{~mL}$, the $\mathrm{CF}$ value obtained in Experiment B, which accounted for the thickness of the animal's abdominal wall, was extrapolated and used in Experiment $\mathrm{C}$.

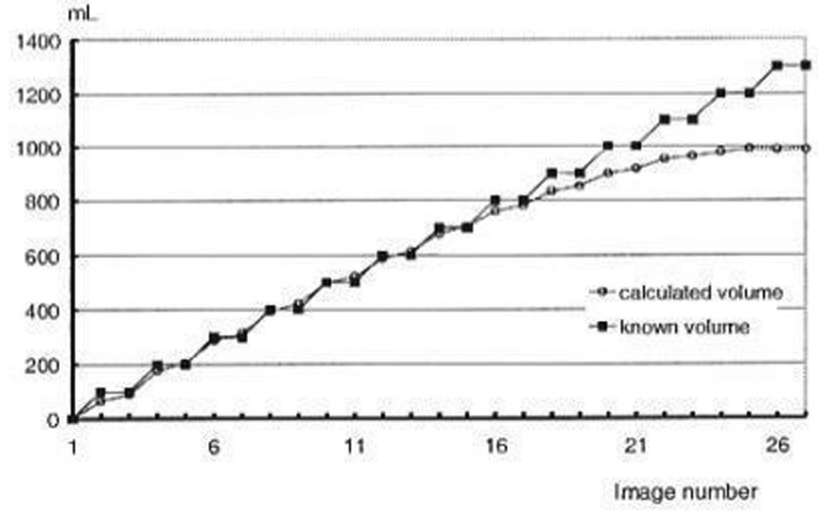

Figure 1 - Comparison between a known volume in the plastic bag and the calculated volume based on radioactivity measurements made by use of the gamma camera (Experiment A). For a volume of $50 \mathrm{~mL}$, the observed averaged error was $17 \%$, and the error was greater than $8 \%$ for volumes larger than $800 \mathrm{~mL}$. For volumes between $100 \mathrm{~mL}$ and $900 \mathrm{~mL}$, there was a significant correlation between the calculated volume and the known volume in the bag
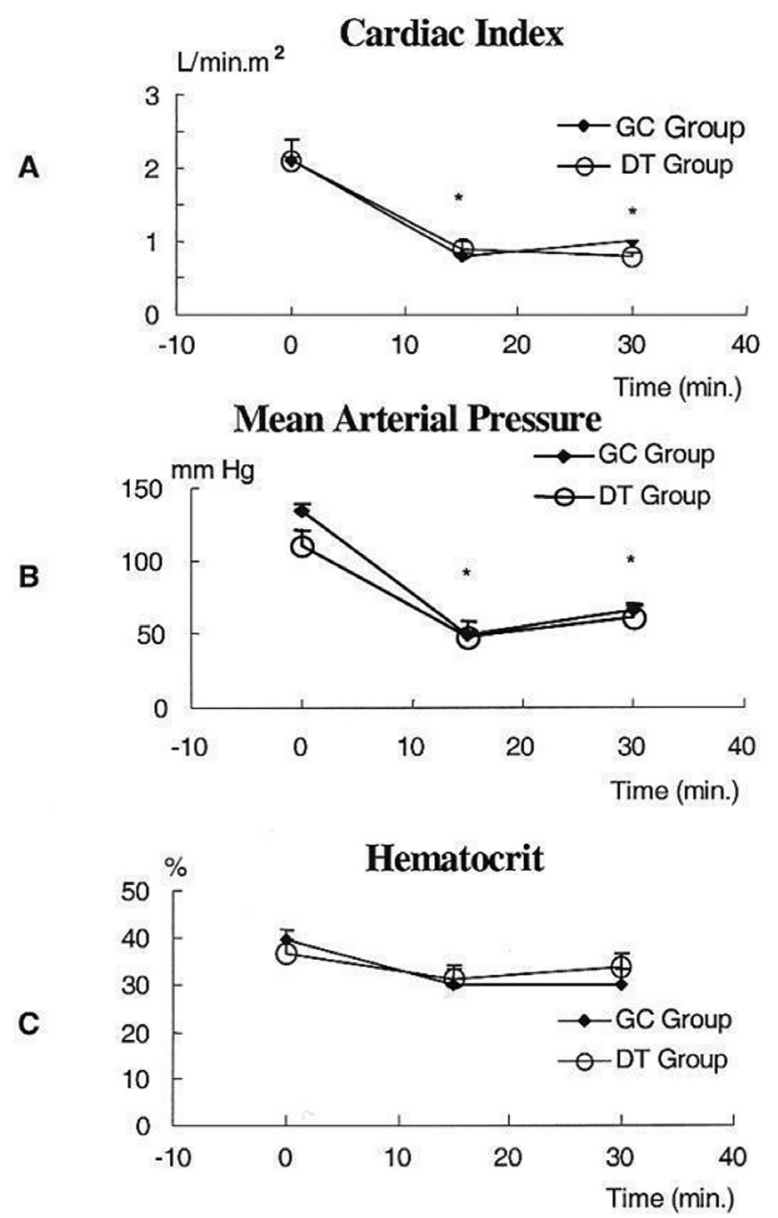

Figure 2 - Cardiac index (Panel A), Mean Arterial Pressure (Panel B), and Hematocrit (Panel C) were measured before (time $=0 \mathrm{~min}$ ) and after (time $=15 \mathrm{~min}$ and $30 \mathrm{~min}$ ) the creation of bilateral iliac artery injuries. No differences were observed in these parameters between the GC and DT groups. Retroperitoneal hematoma formation led to a significant decrease in cardiac index and mean arterial pressure at $15 \mathrm{~min}$ and $30 \mathrm{~min}(\mathrm{p}<0.001)$ 


\section{Experiment C - In Vivo Retroperitoneal Hematoma}

Cardiac index (panel A), mean arterial pressure (panel $\mathrm{B}$ ), and hematocrit (panel C) were measured before (time $=0 \mathrm{~min}$ ) and after (time $=15 \mathrm{~min}$ and $30 \mathrm{~min}$ ) the creation of bilateral iliac artery injuries (Figure 2). No differences were observed in these parameters between the GC and DT groups. Retroperitoneal hematoma formation led to a significant decrease in cardiac index and mean arterial pressure at $15 \mathrm{~min}$ and $30 \mathrm{~min}(\mathrm{p}<0.001)$.

Examples of gamma camera images acquired from one animal during Experiment $\mathrm{C}$, taken before and 5, 10, 15, 30, and 75 minutes after the arterial injuries were created, are shown in Figure 3. Background images and radiation obtained from a syringe containing blood and a radiotracer (see methods) are shown for comparison. Every third image acquired by the gamma camera was used for quantification of the retroperitoneal bleeding volume.

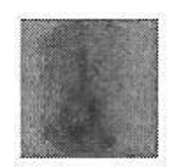

Before injury

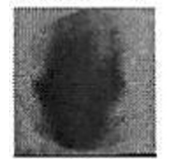

15 minutes after injury

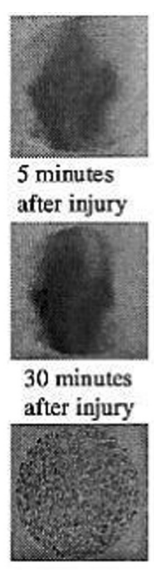

Background
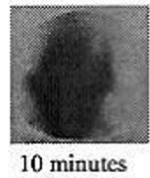

after injury
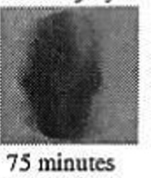
after injury

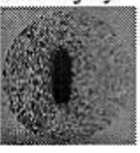

syringe
Figure 3 - Examples of gamma camera images acquired from one animal during Experiment $\mathrm{C}$ taken before and 5, 10, 15, 30, and 75 minutes after the arterial injuries are presented. Background images and radiation obtained from a syringe containing blood and radiotracer (see methods) are shown for comparison

Figure 4 represents the volume of the retroperitoneal hematoma (VRPH) and volume of red cells in the hematoma (VRCH) over time measured at 5-min intervals. Bleeding was more pronounced within the first five minutes after the arterial injury was created, and it ended spontaneously by 15 minutes after the bilateral iliac artery injuries were created.

Comparisons between the volume of the retroperitoneal hematoma (VRPH), volume of red cells in the hematoma (VRCH), and plasma volume of animals in the gamma camera (GC group) or the dilution technique (DT Group) are shown in Figure 5. No significant differences were found when comparing these two methods.

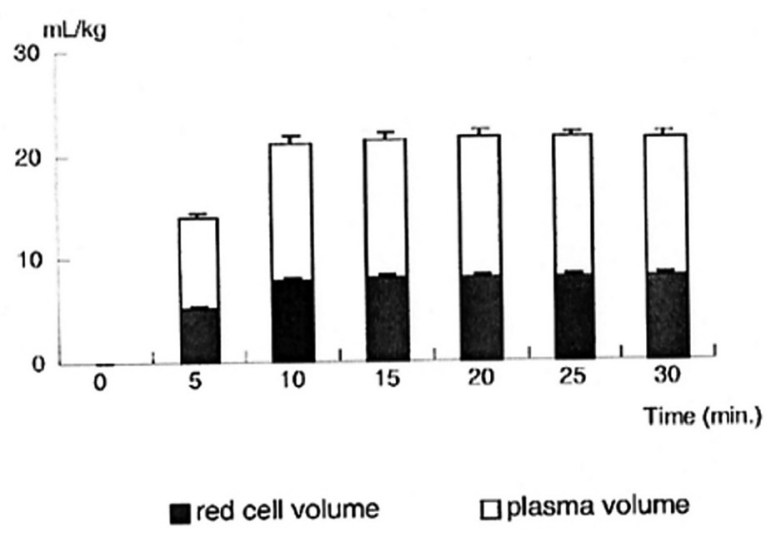

Figure 4 - Volume of the retroperitoneal hematoma (VRPH) and volume of red cells in the hematoma (VRCH) at five-minute intervals in Experiment $\mathrm{C}$ (no fluid resuscitation). Bleeding was more pronounced during the initial 15 minutes after the bilateral iliac artery injuries were created

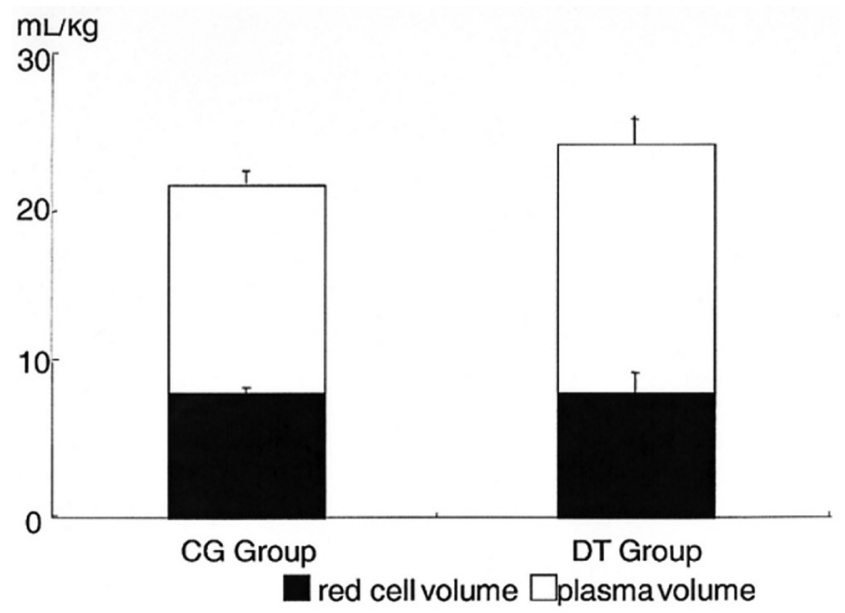

Figure 5-Comparison between the volume of the retroperitoneal hematoma (VRPH), volume of red cells in the hematoma $(\mathrm{VRCH})$, and plasma volume of animals in the GC and DT groups. No differences were found between these two methods

In a comparison between the circulating blood volume (CBV) measured in the GC and DT groups, a significant decrease in the circulating blood volume in both groups was observed, which paralleled the formation of the hematoma (Figure 6).

More importantly, the gamma camera technique was as accurate as the classic dilution technique in determining the total red blood cell volume in the hematoma $(31.2 \pm 1.4 \%$ for the GC group vs. $32.8 \pm 3.9 \%$ for the DT group, $\mathrm{p}>0.7$ ).

\section{Phase II- Resuscitated uncontrolled hemorrhage}

\section{Experiment D - In vivo retroperitoneal hematoma and fluid resuscitation}

A total of 25 animals were used in Experiment D. Four animals were excluded, one due to anemia before the 


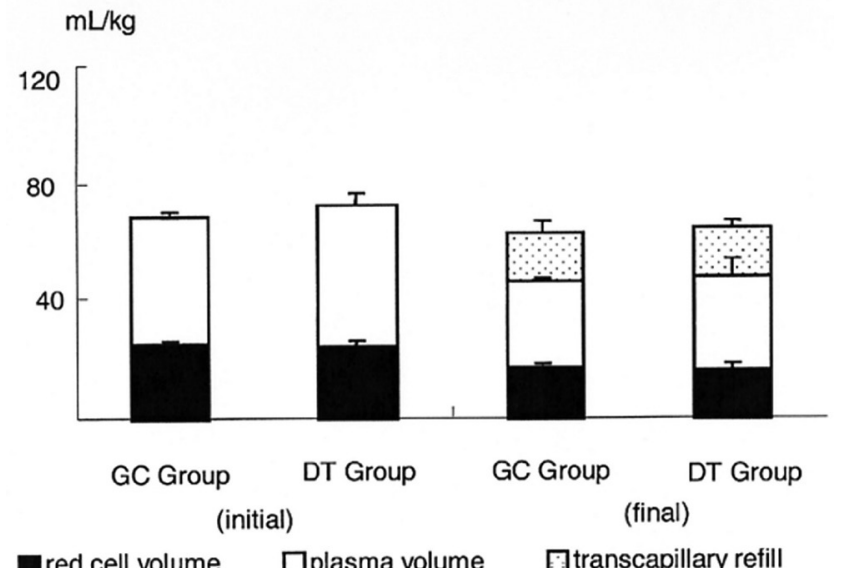

red cell volume

Qtranscapillary refill
Figure 6 - Comparison between the circulating blood volume (CBV) measured in the GC and DT groups. Both methods of measurement were equally accurate in determining total circulating blood volume and its components

beginning of the experiment and three because of bleeding from the retroperitoneum into the peritoneal cavity.

Figure 7 presents the results of MAP, CI, and Htc measurements throughout the experiment. The mean arterial pressure (MAP) decreased significantly during the first fifteen min after the injury, and it increased equally in all groups (panel A). A reduction in cardiac index (CI) was observed 15 min after injury in all groups. After fluid resuscitation, a significant increase in CI was observed in LR- and HSD-treated animals (T45) when compared with the NT group (* $\mathrm{p}<0.05 \mathrm{NT}$ vs. LR and HSD) (panel $\mathrm{B})$. The mean pulmonary artery pressure and pulmonary capillary wedge pressure were similar to the cardiac index. The hematocrit $(\mathrm{Htc})$ was significantly reduced during the first fifteen minutes after the injury. After fluid resuscitation occurred, there was an initial decrease in the Htc in treated groups (from T30 to T45), which was similar in all groups from T45 to T75 (panel C). The hemoglobin level was similar to the hematocrit.

CBV, CRCV, VRPH, VRCH, and TR results are shown in Figure 8.

CBV was equally reduced during the initial 15 minutes after injury in all groups. Fluid resuscitation with subsequent rebleeding led to a decrease in $\mathrm{CBV}$ in both treatment groups, although changes were more pronounced in LRtreated animals ( $<<0.05$ NT vs. LR) (panel A).

The circulating red cell volume (CRCV) decreased slightly during hemorrhage. Fluid resuscitation with subsequent rebleeding led to a decrease in CBV in both treatment groups, although changes were more pronounced in LR-treated animals $(\mathrm{p}<0.05 \mathrm{NT}$ vs. LR; $\mathrm{p}<0.05 \mathrm{LR}$ vs. HSD) (panel B).

Blood volume in the retroperitoneal hematoma (VRPH) at 15 -minute intervals is shown. Bleeding was more
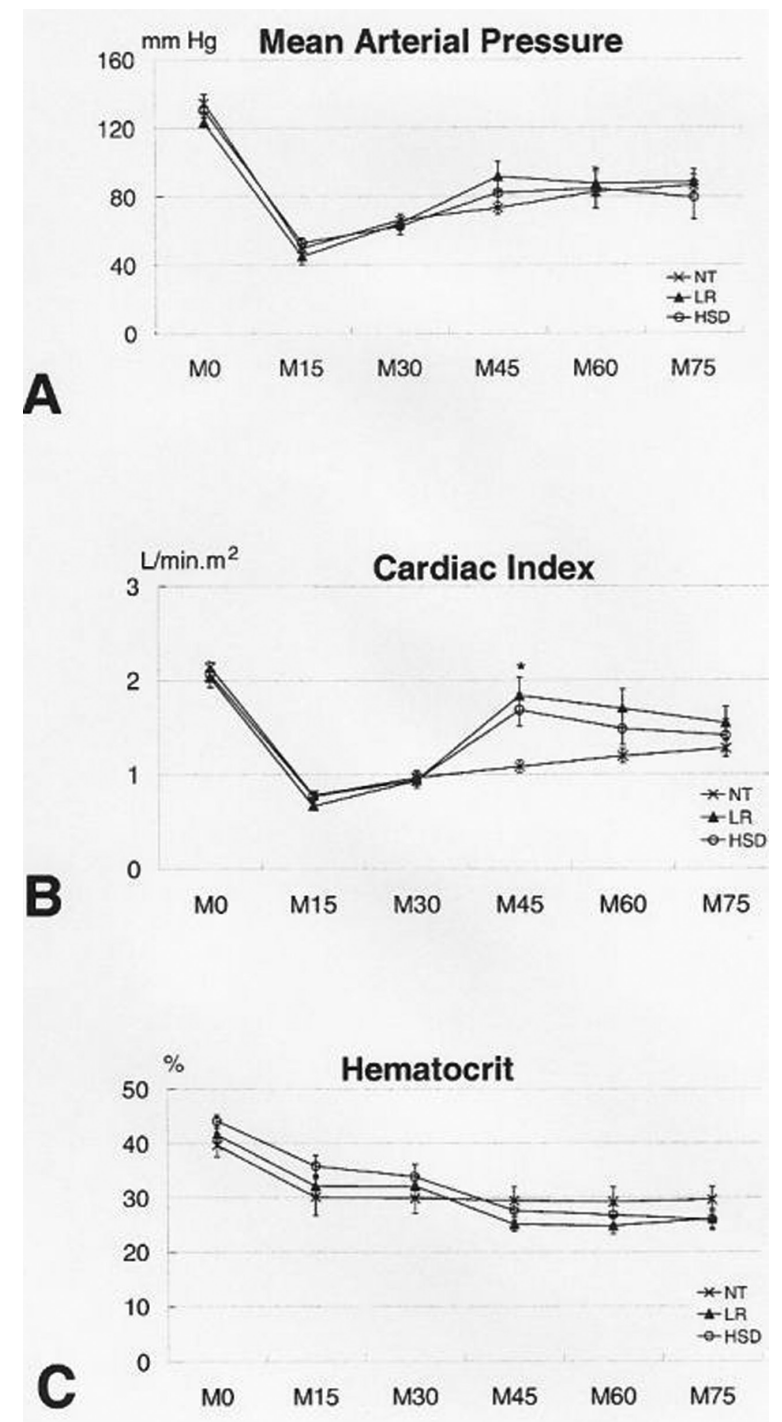

Figure 7 - Panel A - Mean arterial pressure (MAP) decreased significantly during the initial fifteen minutes after the injury, and it increased equally in all groups. Panel B - Reduction in cardiac index $(\mathrm{CI})$ was observed 15 minutes after injury in all groups. After fluid resuscitation, a significant increase in CI was observed in LR- and HSD-treated animals (T45) when compared with the NT group. Panel $\mathrm{C}-\mathrm{Hematocrit}(\mathrm{Htc})$ was similar in all groups during the experiment. * $\mathrm{p}<0.05 \mathrm{CT}$ vs. LR and HSD, $\dagger \mathrm{p}<0.05 \mathrm{CT}$ vs. LR

pronounced in the initial 15 minutes after the bilateral iliac artery injuries were created. Significantly higher VRPH was observed in LR-treated animals when compared to the HSD group, indicating more pronounced rebleeding $(\mathrm{p}<0.05 \mathrm{NT}$ vs. LR and HSD; $p<0.05$ LR vs. HSD) (panel C).

The volume of red cells in the retroperitoneal hematoma (VRCH) at 15-minute intervals is shown. Bleeding was more pronounced in the initial 15 minutes after the bilateral iliac artery injuries were created. Fluid resuscitation with subsequent rebleeding led to an increase in $\mathrm{VRCH}$ in both treated groups. No differences between LR- and HSDtreated animals were observed $(\mathrm{p}<0.05 \mathrm{NT}$ vs. LR and HSD) (panel D). 


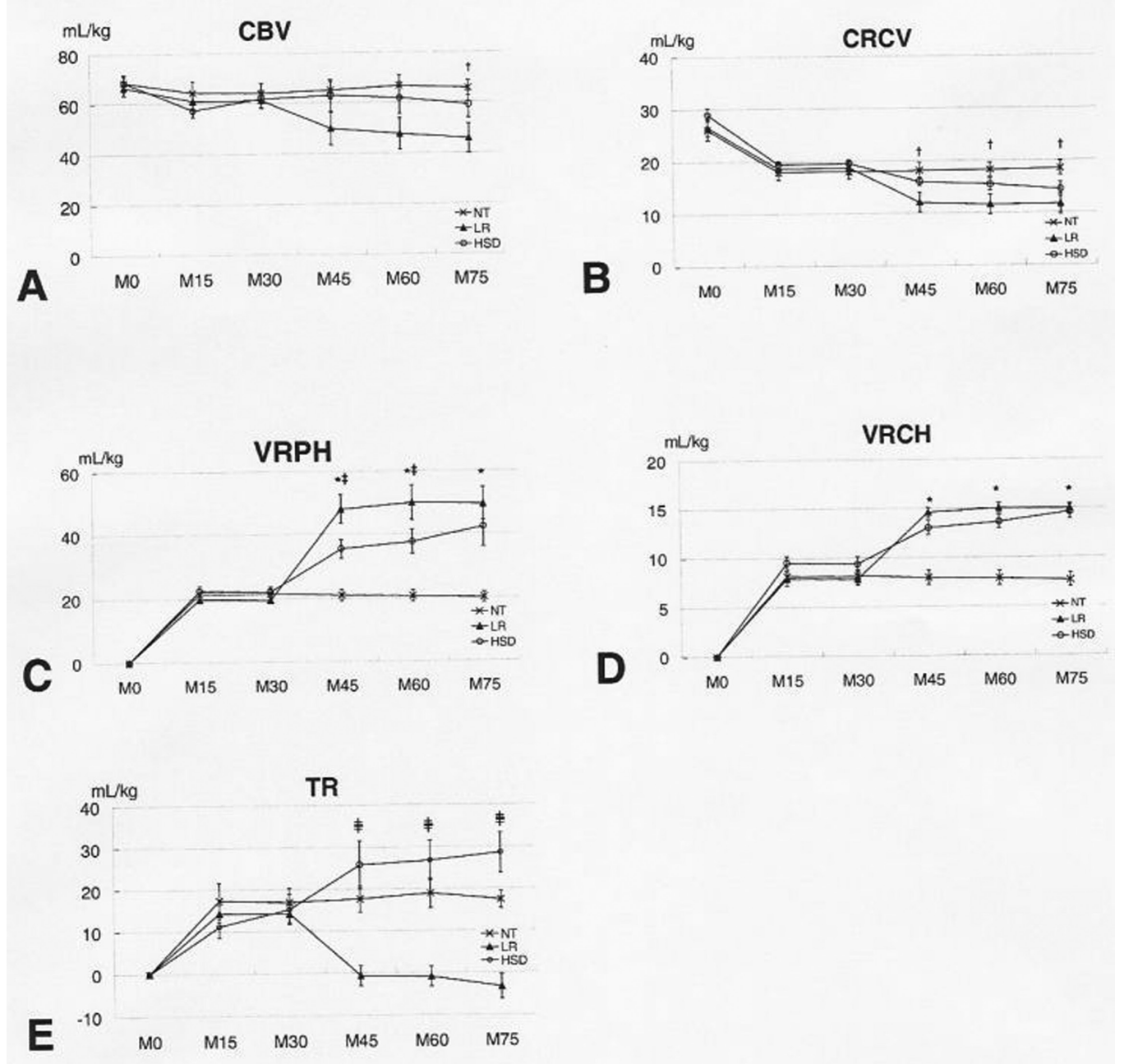

* $\mathrm{p}<0.05$ CT vs. LR and HSD, $\dagger \mathrm{p}<0.05$ CT vs. LR, $\neq \mathrm{p}<0.05$ LR vs. HSD, $\ddagger \mathrm{p}<0.05$ HSD vs. CT and LR

Figure 8 - Panel A -Circulating blood volume (CBV) was reduced equally during the initial 15 minutes in all groups. Fluid resuscitation with subsequent rebleeding led to a decrease in CBV in both treatment groups, although changes were more pronounced in LR-treated animals. Panel B - Circulating red cell volume (CRCV) decreased slightly during hemorrhage. No statistically significant differences were observed when comparing LR and HSD treatments, although LR animals had lower values. Panel C - Blood volume in the retroperitoneal hematoma (VRPH) at 15-minute intervals is shown. Bleeding was more pronounced in the initial 15 minutes after bilateral iliac artery injuries were created. Significantly higher VRPH was observed in LR-treated animals when compared to the HSD group, indicating more pronounced rebleeding. Panel D - Volume of red cells in the retroperitoneal hematoma (VRCH) at 15-minute intervals is shown. No differences between LR- and HSD-treated animals were observed. Panel E - Transcapillary refill increased in all groups during hemorrhage, reached a plateau in the NT group, significantly increased in HSD-treated animals and decreased significantly in the LR group

Transcapillary refill increased in all groups during hemorrhage. Fluid resuscitation determined plateaus in the NT group. It increased in HSD-treated animals and decreased significantly in the LR group $(\mathrm{p}<0.05 \mathrm{NT}$ and HSD vs. LR ) (panel E). In addition, LR-treated animals had negative TR values, indicating transcapillary leaks, while HSD-treated animals had significantly increased transcapillary refill.

\section{DISCUSSION}

The ideal fluid resuscitation used in the treatment of hemorrhagic shock remains a subject of significant debate.
Issues regarding infusion volume, sodium load, rebleeding, pulmonary complications, and ultimately mortality have not yet been solved. Recently, hypertonic resuscitation regained attention due to its immunomodulatory potential.

Evidence points to the fact that hypertonic saline resuscitation decreases the amount of fluid required to restore tissue perfusion when compared to LR. More importantly, however, is the fact that hypertonic saline solutions draw fluid from the interstitium into the intravascular space. This effect is in contrast to isotonic or hypotonic saline solutions, which lead to leaks into the interstitial space of at least two-thirds of the total infusion volume, leading to significant decreases in the 
intravascular volume and formation of tissue edema, further compromising tissue perfusion. In addition, improvements in microcirculatory blood flow, decreased neutrophil adhesiveness, and reduced susceptibility to sepsis after hemorrhagic shock have been documented after hypertonic saline resuscitation. . $^{9} 12,14-15,31-36$

Several animal models have been used to simulate naturally occurring uncontrolled hemorrhage leading to shock by creating mesenteric injury, ${ }^{37}$ major vascular injury, ${ }^{38-39}$ solid organ injury, ${ }^{11,40}$ external hemorrhage, ${ }^{2,4}$ and retroperitoneal hematomas. ${ }^{28}$ Several studies quantified blood loss by weighing surgical sponges, some used the clearance technique with Evans' blue or green indocyanine, and others employed the dilution technique with radiolabeled albumin or red blood cells radiolabeled with ${ }^{99 \mathrm{~m}} \mathrm{Tc},{ }^{41,42}$ or ${ }^{51} \mathrm{Cr} .{ }^{43}$

The gamma camera was developed in 1964. With the development of short half-life radioisotopes and low energy photon emission, this apparatus is now widely employed in diagnostic procedures. It has been used in the evaluation of ventricular function ${ }^{44}$ and in the detection of bleeding sites secondary to upper or lower gastrointestinal pathology. ${ }^{45}$ This study is the first to report use of a gamma camera to reliably quantify major blood loss in an experimental setting.

We selected the present animal model because it reflects the clinical scenario seen in pelvic fractures or vascular injuries contained by the retroperitoneum, allowing us to adequately quantify bleeding volumes before and after fluid resuscitation. Average blood loss in the present study was $31 \%$, which corresponds to a class 3 hemorrhage according to the American College of Surgeons Committee on Trauma. ${ }^{1}$

We compared gamma camera measurements with the dilutional technique and found the gamma camera to be potentially useful for the follow-up of experimental uncontrolled hemorrhage models. When compared to previously described methods, this technique has many potential advantages. It allows for the detection of an area of hemorrhage, quantification of bleeding, and determination of the moment at which bleeding ceases. It is non-invasive and can result in values closer to reality when compared to previously described methods. It is, however, strictly limited to experimental conditions since it requires labeling of blood before hemorrhage begins. Another shortcoming is that the spleen must be removed to avoid distribution of red cells between two dynamically different compartments.

Other important points should be emphasized. The circulating blood volume within the acquisition area of the gamma camera must not vary, although this restriction is of small significance within the abdominal cavity. The use of a second radioisotope is not feasible because it may interfere with image acquisition. Therefore, validation had to be performed in a separate group of experiments.

Bleeding into a confined space, as occurs in the retroperitoneum, is very difficult to quantify. Direct measurements of blood loss are usually performed by draining blood from the abdominal cavity and weighing sponges; however, errors as large as $60 \%$ have been described with these and other less accurate methods. ${ }^{40,46}$ These methods were not applicable to our model because retroperitoneal hematomas are usually formed by clotted blood. Computed tomography scanning has been frequently used in the diagnosis of hemoperitoneum; however, the quantification of retroperitoneal bleeding volume by this method is inaccurate, and its use is contraindicated in patients who are in shock. The use of labeled plasma albumin to evaluate the circulating plasma volume can be misleading because of normal protein leakage into the extravascular compartment, resulting in calculated values higher than the actual values. ${ }^{47}$ Other devices developed to measure bleeding volume have proven to be costly and difficult to use. ${ }^{45}$ Even with the use of ${ }^{99 \mathrm{~m}} \mathrm{Tc}$ or ${ }^{51} \mathrm{Cr}$ labeled red blood cells in the dilution technique, it is difficult to determine the moment at which bleeding stops or resumes. ${ }^{41,43}$ In addition, radiolabeled red cells must be injected at each time point of interest to determine the circulating blood volume after hemorrhage starts. A homogeneous distribution of the labeled red cells in the circulation is always required, which requires 15 minutes to occur. Therefore, it is not possible to determine the circulating volumes at shorter time intervals. The present method covers all of these shortcomings. Employing the two techniques (dilution and gamma camera) to quantify the initial circulating blood volume and the volume of blood present in the retroperitoneal space allows for attainment of important parameters. The circulating blood volume, red cell and plasma volumes after injury, as well as the transcapillary refill can be measured over short time intervals.

The use of a portable gamma camera in the present study introduced a new application to an old method. ${ }^{48}$ This method of monitoring bleeding volumes has a number of positive aspects to be considered in future research: 1) it is possible to quantify blood loss at relatively short time intervals, 2) the natural interruption of bleeding is clearly demonstrated, and 3) the gamma camera is as reliable as the dilution technique in measuring several parameters, as demonstrated in the present study. However, there are a number of restrictions to this method. For each experiment, a value for the correction factor must be determined. Furthermore, the method is strictly for experimental use, and the spleen must be removed if large animals are to be used, to avoid sequestration of volume in the splenic parenchyma 
and the effects of splenic contraction with subsequent changes in the circulating blood volume.

Several studies have reported increased rebleeding with aggressive fluid resuscitation. Strategies for controlling blood loss and therefore the use of blood components have also been reported. ${ }^{49}$ The volume of rebleeding has been related to the sodium load of the solution, amount of fluid resuscitation, and the resultant hemodilution. One research study, ${ }^{4}$ using an animal model of uncontrolled hemorrhage, reported higher rebleeding volumes in animals treated with hypertonic saline with or without dextran, compared to nontreated animals or with animals treated with conventional isotonic resuscitation regimens. ${ }^{4}$ However, the total sodium load was different between groups. Several studies suggested that a state of "controlled hypotension" is probably the best strategy before definitive control of the bleeding site is achieved. $^{2-6}$

Hemodynamic parameters such as the MAP, CI, and Htc have been used to monitor the hemodynamic response to fluid resuscitation and to detect new or recurrent bleeding episodes. MAP decreased during bleeding and increased in all groups after T30. The increase in MAP in the NT group can be explained by the action of compensatory mechanisms, such as vasoconstriction and tachycardia, in an attempt to maintain adequate perfusion to the heart and brain. MAP increased in the HSD and LR groups to levels slightly higher than those in the NT group up to T45, most likely due to fluid infusion. However, MAP decreased again in the resuscitated groups, most likely because of rebleeding. The same observations were made with CI measurements. Hemodilution and rebleeding contributed to decreases in Htc after fluid resuscitation in both resuscitation groups. Changes observed in the hemodynamic parameters and in Htc levels were paralleled by those seen in VRPH, VRCH, CBV, CRCV, and TR. LR-treated animals had higher rebleeding volumes as indicated by increased VRPH compared to the HSD group.

TR following hypertonic saline resuscitation has been demonstrated in animal models of controlled hemorrhage. ${ }^{9-10,12,50}$ In the present study, hemorrhage led to transcapillary refill during the initial fifteen minutes after hemorrhage started in all groups. No transcapillary refill was observed during the shock period (T15 to T30). After fluid resuscitation and despite the occurrence of rebleeding in both resuscitated groups, a clear loss of intravascular volume to the interstitial space (transcapillary leak) was observed in LR-resuscitated animals. In contrast, TR was clearly observed in HSD-treated animals.

\section{CONCLUSION}

This model produces an effective bilateral retroperitoneal hematoma (red cell loss of nearly $31 \%$ ). Fluid resuscitation with either HSD or LR increased MAP, but it also led to rebleeding. Higher rebleeding volumes were observed in LR-treated animals, despite similar sodium loads given to HSD-treated animals. Transcapillary refill was only present in HSD-treated animals. LR-treated animals developed capillary leaks. The combination of increased recruitment of fluid to the intravascular space associated with decreased rebreeding volumes makes HSD, in the present model of uncontrolled hemorrhage, superior to LR resuscitation.

\section{REFERENCES}

1. American College of Surgeons. Advanced Trauma Life Support for Doctors. Instructor Course Manual. 7 ed. Chicago, American College of Surgeons, 2004.

2. Capone AC, Safar P, Stezoski W, Tisherman S, Peitzman AB. Improved outcome with fluid restriction in treatment of uncontrolled hemorrhagic shock. J Am Coll Surg. 1995;180:49-56.

3. Bickell WH, Wall MJ Jr, Pepe PE, Martin RR, Ginger VF, Allen MK, et al. Imediate versus delayed fluid resuscitation for hypotensive patients with penetrating torso injuries. N Engl J Med. 1994;331:1105-9.

4. Rabinovici R, Gross D, Krausz MM. Infusion of small volume of 7.5 per cent sodium chloride in 6.0 per cent dextran 70 for the treatment of uncontrolled hemorrhagic shock. Surg Gynecol Obstet. 1989;169:137-42.

5. Rabinovici R, Krausz MM, Feuerstein G. Control of bleeding is essential for a successful treatment of hemorrhagic shock with 7.5 per cent sodium chloride solution. Surg Gynecol Obstet. 1991;173:98-106.

6. Riddez L, Johnson L, Hahn RG. Central and regional hemodynamics during crystalloid fluid therapy after uncontrolled intra-abdominal bleeding. J Trauma.1998;44:433-9.
7. Velasco IT, Pontieri V, Rocha e Silva M, Lopes OU. Hyperosmotic $\mathrm{NaCl}$ and severe hemorrhagic shock. Am J Physiol. 1980;239:664-73.

8. Kramer GC, Nakayama S, Smith GJ, Perron PR, Gunther RA, Holcroft JW. Comparison of hypertonic and isotonic saline resuscitation of hemorrhagic hypotension. Circ Shock. 1984;13:61-4.

9. Velasco IT, Rocha e Silva M, Oliveira MA, Silva RI. Hypertonic and hyperoncotic resuscitation from severe hemorrhagic shock in dogs: a comparative study. Crit Care Med. 1989;17:261-4.

10. Smith GJ, Kramer GC, Perron BA, Nakayama SI, Gunther RA, Holcroft JW. A comparison of several hypertonic solutions for resuscitation of bled sheep. J Surg Res. 1985;39:517-28.

11. Varicoda EY, Poli de Figueiredo LF, Cruz Junior RJ, Silva LE, Rocha e Silva M. Blood Loss after Fluid Resuscitation with Isotonic or Hypertonic Saline for the Initial Treatment of Uncontrolled Homorrhage Induced by Spleen Rupture. J Trauma. 2003;55:112-7.

12. Kramer GC, Perron PR, Lindsey C, HO HS, Gunther RA, Boyle WA, Holcroft JW. Small-volume resuscitation with hypertonic saline dextran solution. Surgery.1986;100:239-47. 
13. Rocha e Silva M, Velasco IT, Nogueira da Silva RI, Negraes G A, Oliveira MA. Hyperosmotic sodium salts reverse severe hemorrhagic shock: other solutes do not. Am J Physiol.1987;252:751-62.

14. Rocha e Silva M, Poli de Figueiredo LF. Small volume hypertonic resuscitation of circulatory shock. Clinics. 2005;60:159-72.

15. Cruz Jr RJ, Perin D, Silva LE, Yamada-Langui MM, Garrido AG, Poli de Figueiredo LF, et al. Early effects of $7.5 \%$ hypertonic saline solution on splanchnic perfusion after hemorrhagic shock. Acta Cir Bras. 2006;21:106-12.

16. Younes RN, Aun F, Kawarara NT, Oliveira MR. Hypertonic sodium chloride $(7.5 \%)$ improves the hemodynamics of hypovolemic patients. Braz J Med Biol Res. 1986;19:498A.

17. Vassar MJ, Perry C, Holcroft JW. Analysis of potencial risks associated with $7.5 \%$ sodium chloride resuscitation of traumatic shock. Arch Surg. $1990 ; 125: 1309-15$.

18. Younes RN, Aun F, Accioly CQ, Casale LPL, Szajnbok I, Birolini D. Hypertonic solutions in the treatment of hypovolemic shock: a prospective, randomized study in patients admitted to the emergency room. Surgery. 1992;111:380-5.

19. Vassar MJ, Fischer RP, O'Brien PE, Bachulis BL, Chambers JA, Hoyt $\mathrm{DB}$, et al. A multicenter trial for resuscitation of injured patients with 7.5\% sodium chloride. The effect of added dextran 70. Arch Surg. 1993;128:1003-13.

20. Maningas PA, Mattox KL, Pepe PE, Jones RL, Feliciano DV, Burch JM. Hypertonic saline-dextran solutions for the prehospital management of traumatic hypotension. Am J Surg. 1989;157:528-33.

21. Mattox KL, Maningas PA, Moore EE, Mateer JR, Marx JA, Aprahamian C, et al. Prehospital hypertonic saline/dextran infusion for post-traumatic hypotension. The USA Multicenter Trial. Ann Surg. 1991;213:482-91.

22. Younes RN, Aun F, Ching CT, Goldenberg DC, Franco MH, Miura FK, et al. Prognostic factors to predict outcome following the administration of hypertonic/hyperoncotic solution in hypovolemic patients. Shock. 1997;7:79-83.

23. Wade CE, Grady JJ, Kramer GC. Efficacy of hipertonic saline dextran (HSD) in patients with traumatic hypotension: meta-analysis of individual patient data. Acta Anaesthesiol Scand. 1997;41:77-9.

24. Wade CE, Grady JJ, Kramer GC. Efficacy of hypertonic saline dextran fluid resuscitation for patients with hypotension from penetrating torso injuries. J Trauma. 2003;54(5 Suppl):S144-8.

25. Griecco JG, Perry JF. Retroperitoneal hematoma following trauma: its clinical importance. J Trauma. 1980;20:733-6.

26. Baric D, Kukoc M, Vidak V, Saric D, Planjar M, Radonic V, et al. Retroperitoneal hematoma as a consequence of blunt abdominal injury. Acta Chir Iugosl. 1989;36 Suppl 1:148-50.

27. Goinz WA, Rodriguez A, Lewis J, Brathwaite CE, James E. Retroperitoneal hematoma after blunt trauma. Surg Gynecol Obstet. 1992; 174:281-90.

28. Cruz Jr RJ, Perin D, Silva LE, Valerio FB, Branco MC, Poli de Figueiredo $\mathrm{LF}$, et al. Radioisotope blood volume measurement in uncontrolled retroperitoneal hemorrhage induced by a transfemoral iliac artery puncture. Injury. 2001;32:17-21.
29. Rocha AFG. Medicina nuclear. In: Rocha AFG. Bases físicas. Rio de Janeiro: Guanabara Koogan, 1976. Cap.1, p.3-27.

30. Kowalsky RJ, Perry JR. Radiopharmaceuticals.In: nuclear medicine practice. Connecticut: Appleton \& Lange, 1987, cap.12, p.411-33.

31. Kreimeier U, Bruckner UB, Niemczyk S, Messmer K. Hyperosmotic saline dextran for resuscitation from traumatic- hemorrhagic hypotension: effect on blood flow. Circ Shock. 1990; 32:83-99.

32. Rizoli SB, Kapus A, Fan J, Li IH, Marshall C, Rotstein OD. Immunomodulatory effects of hypertonic saline resuscitation on the development of lung inflammation following hemorrhagic shock. J Immunol. 1998;161:6288-96.

33. Yada-Langui MM, Anjos VE, Coimbra R, Sannomyia P, Rocha e Silva M. Comparative effects of the treatments with lactated ringer's, hypertonic saline oe pentoxifyline on microcirculation after hemorrhagic shock. In: 30th International Educational and Scientific Synposium Critical Care Medidicine, 2000, São Francisco. Critical Care Medicine, 2001. v. 28. p. A 138-A 138.

34. Yamada-Langui MM, Anjos VE, Coimbra R, Sannomyia P, Rocha e Silva M. Hypertonic saline and Pentoxifyline after hemorrhagic shock. In: Twenty-Third Annual Conference on Shock Snowbird, Utah, 2000, Utah. Shock - Injury, Inflammation, and Sepsis: Laboratory and Clinical Approaches. v. 13. p. 152-152.

35. Coimbra R, Junger WG, Hoyt DB, Liu FC, Loomis WH, Evers MF, et al. Immunosuppression following hemorrhage is reduced by hypertonic saline resuscitation Surg Forum. 1995;46:84-7.

36. Coimbra R, Hoyt DB, Junger WG, Angle N, Wolf P, Loomis W, et al. Hypertonic saline resuscitation decreases susceptibility to sepsis after hemorrhagic shock. J Trauma. 1997;42:602-6.

37. Gross E, Landau EH, Assaila A, Kraus MM. Is hypertonic saline resuscitation safe in 'uncontrolled' hemorrhagic shock? J Trauma. 1988;28:751-6.

38. Bickell WH, Bruttig SP, Wade CE. Hemodynamic response to abdomina aortotomy in anesthetized swine. Circ Shock. 1989;28:321-2.

39. Bickell WH, Gregory A, Bruttig SP, Millnamow MA, O’Benar JO, Wade CE. The detrimental effects of intravenous crystalloid after aortotomy in swine. Surgery. 1991;110:529-36.

40. Matsuoka T, Wisner DH. Liver injury as a model of uncontrolled hemorrhagic shock: resuscitation with different hypertonic regimens. J Trauma. 1995;39:674-80.

41. Korubin V, Maisey MN, Mcintyre PA. Evaluation of Technetium-labeled red cells for determination of red cell volume in man. J Nucl Med. 1972;13:760-2.

42. Dewanjee MK. Binding of Tc ion to hemoglobin. J Nucl Med.1974;15:7036.

43. Gray SJ, Sterling K. Determination of circulating red cell volume by radioactive chromium. Science. 1950;112:179-80.

44. Johnson LL, Tauxe LE. Radionuclide assessment of ventricular function Curr Probl Cardiol.1994;10:589-636.

45. Thorne DA, Datz FL, Remley K, Christian PE. Bleeding rates necessary for detecting acute gastrointestinal bleeding with technetium99 m-labeled red blood cells in an experimental model. J. Nucl Med.1987;28:514-20. 
46. Darden ML. Blood loss determination. AORN J.1981;33:1368-80.

47. Williams JA, Fine J. Measurement of blood volume with a new apparatus N Engl J Med.1961;264:842-8.

48. Sinosaki S, Sallum EA, Pereira FL, Hondo FY, Abe R, Coimbra R, et al. A new method for measuring blooding loss with a gamma camera, in a canine model of uncontrolled hemorrhage. Shock. 1999;11:34.
49. Souza HJ, Moitinho RF. Strategies to reduce the use of blood components in cardiovascular surgery. Rev Bras Cir Cardiovasc. 2008;23:53-9.

50. Prist R, Rocha e Silva M, Scalabrini A, Coelho IJC, França ESV, Meneghetti $\mathrm{C}$, et al. A quantitative analysis of transcapillary refill in severe hemorrhagic hypotension in dogs. Shock. 1994;1:188-95. 